\title{
OS MBYÁ-GUARANI ATRAVÉS DA SUA CULINÁRIA DOCE
}

CÁTIA SIMONE DA SILVA ${ }^{1}$

UFPel

\section{RESENHA}

TEMPASS, Mártin César. A doce cosmologia Mbyá-Guarani: uma etnografia de saberes e sabores. Curitiba: Appris, 2012. 514 p.

"A doce cosmologia Mbyá-Guarani: uma etnografia de sabores e sabores" (Editora Appris, 2012, 514 páginas), do antropólogo Mártin César Tempass, aborda a sociocosmologia mbyá-guarani a partir das suas práticas alimentares, com foco nas relações que os indivíduos deste grupo mantêm com os seres que habitam a natureza e a sobrenatureza. Com esses seres, todos dotados de perspectivas subjetivas, são mantidas relações recíprocas, produtivas, densas, algumas vezes perigosas e muitas vezes criando ou construindo novos seres.

\footnotetext{
${ }^{1}$ Cátia Simone da Silva, discente do Bacharelado em Antropologia na Universidade Federal de Pelotas, Integrante do Núcleo de Etnologia Ameríndia (NETA) e do Núcleo de Estudos sobre Populações Costeiras e Saberes Tradicionais (NECO). Editora do blog www.antropologiasocial.com.br e do site www.antropologiaufpel.com.br . E-mail: catia@antropologiasocial.com.br .
}

Espaço Ameríndio, Porto Alegre, v. 6, n. 2, p. 276-282, jul./dez. 2012. 
Mártin César Tempass nos apresenta como estas relações ocorrem de forma interdependente e encadeada desde as formas de obtenção dos alimentos tradicionais dos Mbyá-Guarani, passando pelas fases de estocagem, distribuição e processamento, até chegar ao consumo alimentar propriamente dito. Todas essas fases são formadoras e constituintes da pessoa mbya-guarani. Pelo exposto percebe-se que o livro gira em torno da culinária mbyá-guarani, mas não se limita a ela. A culinária mbyá-guarani, como a culinária de qualquer outro agrupamento humano, está fortemente entrelaçada com as demais instituições sociais e aspectos culturais deste grupo indígena. Desta forma, como argumenta o autor, a compreensão da culinária mbyá-guarani passa pela compreensão do grupo e dos seus aspectos culturais como um todo.

O livro dá conta desse propósito a partir de um cuidadoso equilíbrio entre referenciais teóricos e dados bibliográficos e um rico material de campo, resultado de inúmeras pesquisas etnográficas que o autor realizou junto aos coletivos mbyá-guarani do estado do Rio Grande do Sul, durante longos anos do seu período acadêmico, desde a graduação até o pós-doutorado. Segundo o autor, o livro também tem o objetivo de reparar alguns dos seus trabalhos anteriores. Isso porque, com um trabalho de campo mais longo e cuidadoso, o autor percebeu que muitos dos seus trabalhos anteriores careciam de maior profundidade e melhores interpretações.

Trabalhando com os Mbyá-Guarani, grupo indígena que habita parcelas do território do Brasil, Argentina, Uruguai e Paraguai, Tempass estranha o fato das pesquisas sobre esse grupo serem embasadas quase exclusivamente em outros trabalhos com grupos amazônicos atuais, muito distantes geográfica e culturalmente dos Guarani. A partir do seu estágio de pós-doutorado, realizado na Universidade de San Martín, em Buenos Aires, o autor defende um maior diálogo com os pesquisadores das regiões e países onde habitam os Mbyá-Guarani. Precisamos, segundo o autor, conhecer mais e melhor as pesquisas realizadas na Argentina, Uruguai e Paraguai.

O livro foi escrito para ser acessível a uma grande gama de leitores, dos simplesmente curiosos até os especializados. O autor justifica essa postura em função do grande e variado número de 
profissionais que pesquisam, interagem e interferem na cultura mbyáguarani - funcionários públicos, técnicos agrícolas, assistentes sociais, nutricionistas, historiadores, médicos, enfermeiros, odontologistas, advogados, pedagogos, arquitetos, etc.

Tempass também explica que muito já foi escrito sobre esse grupo, mas, no entanto, temas relacionados ao xamanismo e à cosmologia ainda são pouco compreendidos, não por culpa dos pesquisadores, mas porque os Mbyá-Guarani, no intuito de preservar a sua cultura, mantêm muitos aspectos em segredo frente aos juruá (brancos). No entanto, como é muito observado no decorrer do livro, a culinária mbyá-guarani está estreitamente relacionada e depende das concepções xamânico-cosmológicas do grupo. Desta forma, a alimentação mbyá-guarani passa obrigatoriamente pela opy (casa de rezas), edificação indispensável para a sobrevivência física e espiritual do grupo. Outro aspecto indispensável para a sobrevivência física e espiritual do grupo é a ocupação de um meio ambiente específico, onde todos os seres do cosmos possam existir e se relacionar. Esse ambiente singular é raro de ser encontrado atualmente, e muitas das poucas áreas que restam com as características necessárias não estão mais em posse dos Mbyá-Guarani. O livro de Tempass visa auxiliar na reversão deste quadro. Segundo o autor, o livro é destinado "para atestar e divulgar a necessidade urgente que a etnia tem em recuperar as terras que eram ocupadas pelos seus ancestrais" (TEMPASS, 2012, p. 30). Pois somente nas terras tradicionais é possível a obtenção da alimentação tradicional e a correta vivência do modo de ser mbyá-guarani.

"O alimento é o ambiente". A partir disso o autor buscou diversas áreas ecológicas para os seus estudos. Ao invés de um grande número de interlocutores, as etnografias se deram em várias condições ambientais: aldeias de Itapuã, Petim, Cantagalo, Estiva, Coxilha da Cruz, Lami, Passo Grande, Flor de Campo, Varzinha, Cantagalo 3, Lomba do Pinheiro e Ñancapetum, todas no Rio Grande do Sul².

\footnotetext{
${ }^{2}$ Os Mbyá-Guarani buscam lugares específicos para viverem, porém diante da perda de seus territórios tradicionais para a sociedade envolvente, muitos aldeamentos mbyá-guarani ocorrem longe das condições ambientais necessárias. E os quadros ambientais nesses casos são muito diversificados: desde os casos de aldeias com mata, mas com pequena extensão territorial, até aquelas localizadas nas margens das rodovias.
}

Espaço Ameríndio, Porto Alegre, v. 6, n. 2, p. 276-282, jul./dez. 2012. 
Apesar das etnografias terem sido produzidas nas aldeias do Rio Grande do Sul, Tempass advoga que as análises podem ser estendidas para a totalidade da população mbyá-guarani. Isso é possível, segundo o autor, em razão da grande mobilidade que lhes é própria. A circulação de indivíduos entre as várias aldeias leva à uniformização das práticas alimentares, sempre atualizadas porque a mobilidade é constante. Então os mesmos quadros alimentares podem ser observados nas mais diversas aldeias mbyá-guarani, inclusive nas mais distantes, variando somente no que tange ao acesso aos recursos naturais.

A culinária mbyá-guarani tem como destaque a predominância de sabores doces. Mesmo nos alimentos salgados, o paladar mbyáguarani consegue perceber os sabores doces. E o sabor doce é muito importante para os Mbyá-Guarani. Tempass, a partir de vasto levantamento bibliográfico, identifica essa mesma importância para os demais agrupamentos humanos. E, diante disso, no segundo capítulo, intitulado "A amarga história do doce açúcar", Tempass traz um breve relato sobre a história do açúcar e suas representações para a humanidade. $O$ autor elegeu o açúcar como fio condutor para o capítulo, pois é o alimento mais doce conhecido e utilizado em todo o mundo.

Ainda no segundo capítulo, o autor, a partir do doce, relaciona a alimentação indígena com a dos não indígenas e apresenta um interessante quadro sobre o processo de formação da culinária brasileira. Se antes se ignorava a produção doceira por parte dos indígenas, agora Tempass mostra a grande contribuição desses grupos para a doçaria nacional. Os grupos indígenas, no processo de construção histórica, contribuíram muito para que atualmente o Brasil ficasse conhecido como o país do doce, sendo os doces brasileiros mais doces do que os de outros países.

No terceiro capítulo Tempass apresenta dois pontos-chaves do seu trabalho junto aos Mbyá-Guarani: as formas de obtenção dos alimentos tradicionais e as relações com os já (seres sobrenaturais donos e controladores dos alimentos). Ambas estão relacionadas e podem ser compreendidas a partir da dualidade da alma dos MbyáGuarani. Assim como os Mbyá-Guarani, os seus alimentos tradicionais também são duais, ou seja, sagrados e/ou telúricos. Tempass diz que a forma de obtenção tradicional dos alimentos é determinante para essa 
classificação e também para a produção de alimentos doces que constroem pessoas igualmente doces, formando uma sociedade alicerçada em relações dóceis. Porém num suspense literário, o autor só fala dos doces mbyá-guarani nos capítulos finais do livro, reunindo todos os aspectos abordados em torno do doce.

Sobre as plantas e seus já, o autor diz que as almas dos alimentos possuem divindades denominadas já, ou seja, seus donos, porém estas divindades encontram-se no mundo sobrenatural e cada espécie vegetal deve ser cultivada respeitando os preceitos do seu já. O mesmo vale para as atividades de caça, pesca e coleta, desenvolvidas segundo os preceitos de cada já responsável pelo alimento. Um dos principais preceitos alimentares do grupo é distribuir e/ou repartir todo e qualquer alimento obtido. Não se pode guardar um alimento para si enquanto que um outro necessita dele. Essa distribuição obrigatória é a base da reciprocidade alimentar do grupo e em função disso a comida mbyá-guarani acaba sendo "pública". É preciso mostrar para os outros o que se tem para comer.

Tempass informa que os Mbyá-Guarani mantêm relações de tipo social com os animais e com as plantas, mas essas relações sempre são mediadas pelos já. Assim, essas relações se dão mais no eixo vertical do que no horizontal. "As relações sociais dos Mbyá-Guarani são muito mais com seres sobrenaturais, do que com os animais" (TEMPASS, 2012, p. 217).

No capítulo quatro o autor analisa a culinária para o aguyje estado de perfeição do ser, que conduz à divindade. Tempass procura evidenciar as formas de preparação e consumo dos alimentos tradicionais, dando destaque ao "ambiente" em que as atividades ocorrem. Ambiente tanto físico como anímico e social, que possibilita a preparação do alimento tradicional. Os Mbyá-Guarani seguem uma série de regras para a obtenção dos alimentos e existem regras também para o preparo e consumo dos alimentos tradicionais. São elas que controlam o aguyje, a saúde e a organização social. E o objetivo de todo MbyáGuarani é alcançar o aguyje para tornar-se uma divindade. Esse objetivo só será alcançado se os Mbyá-Guarani respeitarem algumas regras cosmológicas diretamente ligadas à alimentação do grupo. Sendo a alimentação uma das chaves para o destino dos indivíduos e também do 
grupo, a culinária se configura uma importante fonte de poder social, de poder feminino. A partir da alimentação pode-se compreender toda a organização sociocosmológica do grupo.

O autor acredita que a dualidade não se dá só para a alma, mas também para os seus corpos. Os corpos dos Mbyá-Guarani (seres que se encontram na sociedade) são constituídos de porções de natureza e sobrenatureza. O mesmo vale para tudo que existe no mundo mbyáguarani, tudo é constituído a partir dos três domínios cosmológicos, não sendo possível a separação analítica dos domínios da natureza, da sociedade e da sobrenatureza. Tudo é construído em conjunto, com os seres dos três domínios, mas pertencem somente a uma condição das três possíveis. Ou se é um ser da natureza (animal, planta, mineral...), ou se é um ser humano, ou se é uma divindade. Mas essas três condições são frágeis e podem ser mudadas a qualquer momento. Como argumenta o autor, entre os Mbyá-Guarani, quem hoje é humano amanhã poderá ser um animal ou uma divindade.

No quinto capítulo, intitulado "Os indigestos juruá", o autor informa que desde o início da colonização os portugueses se valeram dos alimentos dos indígenas para conseguirem se estabelecer no Brasil, mas foram também os colonizadores os responsáveis pela dizimação de vários grupos indígenas. Nesse contexto eles perderam as suas terras e hoje alguns vivem em aldeias sem condições práticas e simbólicas de sobrevivência por estarem em áreas ambientalmente degradadas, sem matas ou rios e/ou com solos fracos que não favorecem a horticultura. Ainda há outros grupos que vivem acampados na beira das rodovias. Esse quadro faz com que os Mbyá-Guarani acionem uma série de estratégias alternativas para a obtenção dos seus alimentos. Trata-se de uma culinária de emergência, bastante diferente da ideal tradicional, mas que não deixa de ser orérembiú (nossa comida). Nesse capítulo Tempass mostra como os Mbyá-Guarani mantêm a sua tradicionalidade apesar da adversidade.

O último capítulo do livro, "Quanto mais doce, melhor..." (que foi o título da tese de doutorado de Tempass), trata dos doces na cosmologia Mbyá-Guarani. Não só dos alimentos doces, mas também de posturas e comportamentos doces que são a base da organização social dos Mbyá-Guarani. A doçura se encontra em tudo. É através dela 
que os indígenas desse grupo obtêm a alegria necessária para viverem nesse mundo. Se não estiverem alegres a sua alma pode voltar para o domínio sobrenatural (de onde é originária), levando os indivíduos à morte. E a alegria dos Mbyá-Guarani também é um dos quesitos para atingir o aguyje. Por isso eles não costumam fazer o que não gostam e também não comem alimentos que não gostam.

Apesar do tamanho do livro (514 páginas), o autor afirma que ainda há muito para ser trabalhado sobre o assunto, que a temática proposta ainda tem muitas lacunas abertas. Mas a sua contribuição em relação à alimentação mbyá-guarani auxiliará muitos interessados pelas temáticas junto a esses grupos.

Retomando tudo o que foi exposto no livro, o autor aponta a urgência nos reconhecimentos e nas demarcações de terras para os Mbyá-Guarani, para assim poderem retomar a sua vida conforme a sua cultura... com seus alimentos tradicionais... com alegria, saúde, fartura e paz.

\section{Referência bibliográfica}

TEMPASS, Mártin César. A doce cosmologia Mbyá-Guarani: uma etnografia de saberes e sabores. Curitiba: Appris, 2012. 514 p. 